\title{
Culture moderates the association between social expectations regarding helping and positive affect
}

\author{
Claudia GHERGHEL1),2),*, Takeshi HASHIMOTO'), Jiro TAKAI') \\ 1)Nagoya University Graduate School of Education and Human Development \\ 2)Japan Society for the Promotion of Science \\ 3)Shizuoka University Faculty of Humanities and Social Sciences
}

\begin{abstract}
Previous research suggests that individuals from interdependent cultures have more congruent views of agency and social obligations. This study aimed to confirm these findings by investigating the moderating effects of culture on the association between perceived social expectations regarding helping and affect. Japanese $(n=164)$ and American $(n=177)$ adults recalled a recent situation in which they helped someone and responded to a questionnaire regarding need satisfaction and affect. As expected, the Japanese subjects showed a stronger positive association between the perceived social expectation that they should help and positive affect than the Americans. For Japanese, the perceived social expectation that they should help increased satisfaction of the need for competence, leading to a more positive affect, while for Americans, the perceived social expectation that they should help reduced satisfaction of the need for autonomy, which in turn, reduced positive affect.
\end{abstract}

Key Words: culture, self-determination, social expectation, helping behavior, positive affect

Self-determination theory posits that autonomously motivated helping is conducive to experiencing positive affect through satisfaction of autonomy, competence, and relatedness needs (Weinstein \& Ryan, 2010). However, what people consider an autonomous reason to be may differ with culture. In Western research, responding to social expectations is conceptualized as a controlled (nonautonomous) motive for engaging in an activity (Jiang \& Gore, 2016), which can impede the satisfaction of basic psychological needs. In contrast, for people of interdependent cultures, meeting social expectations may not be perceived as controlling (Buchtel et al., 2018; Janoff-Bulman \& Leggatt, 2002; Miller, Das, \& Chakravarthy, 2011). Previous research reveals that participants from Asian interdependent cultures show a stronger positive association between agentic (want) and obligatory motives for helping (duty, social expectation), as well as between meeting their obligations and positive emotions, suggesting that they have internalized role expectations more than their European heritage counterparts (Buchtel et al., 2018). One possible reason for this cultural moderation is stronger endorsement of role ethics in Asian cultures (Buchtel et al., 2018), as individuals who hold moral values pertaining to duty fulfilment and abiding by community norms would be likely to show more internalization of social expectations to help distant others (Gherghel, Nastas, Hashimoto, Takai, \& Cargile, 2019). Therefore, the degree of internalization of social expectations to help might be influenced by a culture-bound moral discourse.

Comparing an Asian interdependent culture (Japan) to an European-heritage independent one (U.S.), this study

* Corresponding Author e-mail: clemghe@gmail.com

Online Appendix: https://doi.org/10.2130/jjesp.1917 
Gherghel, Hashimoto \& Takai: Culture moderates the association between social expectations regarding helping and positive affect

aims to investigate the moderating effect of culture on the association between agency (feeling of choice and desire to engage in an activity, corresponding to autonomous motivation) and obligation (perceived social expectations to help), as well as the relationship between perceived social expectations to help and affect. Given that Janoff-Bulman and Leggatt (2002) revealed that the greatest cultural differences appear when targets are of medium-closeness, we focused on the context of helping an acquaintance. As simple recollection of past helping behavior can influence one's present mood (Wiwad \& Aknin, 2017), we asked participants to recall an act of kindness, evaluate their agentic (desire) and obligated motivation (perception of social expectation) to help the target, and report on their current affect. Unlike past research which mainly used scenarios and sampled university students (Buchtel et al., 2018; Janoff-Bulman \& Leggatt, 2002), we chose to ask adult participants about their actual helping experiences, in an effort to fortify the generalizability of findings. Given the above arguments, we expect Japanese to internalize social expectations more than Americans, showing a stronger positive association between desire to help and perceived social expectations (Hypothesis 1), and a stronger positive relationship between perceived social expectations and positive affect (Hypothesis 2). Furthermore, to investigate whether endorsement of a duty-based moral discourse leads to the internalization of social expectations (Gherghel et al., 2019), we measured individuals' endorsement of community ethic. We expect that participants who endorse community ethic would show a stronger positive association between desire to help and perceived social expectation, and between perceived social expectation and positive affect (Hypothesis 3). Finally, we explore a mediational model explaining why social expectations are differently related to affect in the two cultures, by focusing on the mediating role of basic psychological need satisfaction. If perceived social expectations are a form of obligated motivation to help, they could reduce satisfaction of basic psychological needs, which, in turn, reduce positive affect (U.S. mediation model), but if social expectations are a form of agentic motivation, they might increase satisfaction of basic psychological needs and, thus, positive affect (Japan mediation model).

\section{Method}

\section{Participants}

Data were collected on the crowd-sourcing platforms of Amazon Mechanical Turk in the U.S. and Lancers, in Japan. The responses of 164 Japanese (86 males, $M_{\text {age }}=41.49$, $S D=9.72,57.9 \%$ college graduates) and 177 U.S. participants (93 males, $M_{\text {age }}=37.34, S D=11.26,51.9 \%$ college graduates, $72.9 \%$ Euro-Americans) were analyzed (for exclusion criteria see supplementary Table S1). There were no gender proportion differences between the two samples $\left(\chi^{2}=0.01, p=.92\right)$, but Japanese were older than Americans $(t=3.62, p<.001)$.

\section{Procedure}

Participants were requested to recall their most recent act of kindness toward an acquaintance (neither family or close friend, nor stranger), and spend at least 3 minutes writing down the details of the interaction, focusing on what they had done and how it had made them feel.

\section{Measures}

First, participants' agentic (how much they wanted) and obligated motivation (how much their acquaintance expected them) to engage in the prosocial act they had just recalled was measured ( $1=$ Not at all, $7=$ Very much). Basic psychological need satisfaction was measured using the nine satisfaction items from the Balanced Measure of Psychological Needs Scale (Sheldon \& Hilpert, 2012), which is comprised of three factors: autonomy need satisfaction, competence need satisfaction, and relatedness need satisfaction. The scale was translated into Japanese through back-translation by a team of bilingual researchers (for factorial structure and measurement invariance of the scale, see supplementary Table S2). Affect was measured with the PANAS (Watson, Clark, \& Tellegen, 1988; Kawahito, Otsuka, Kaida, \& Nakata, 2011), a scale comprised of two factors: positive affect and negative affect. We also added four items to measure happiness (Kitayama, Markus, \& Kurokawa, 2000). To measure endorsement of duty-based ethics, the Ethic of Community subscale (10 items) from the Autonomy, Community and Divinity Scale (Guerra, Giner-Sorolla, \& Vasiljevic, 2013) was included. To check whether there were any cultural differences in closeness between participants and targets ("acquaintance” might mean different 
things in the two cultures), we used the Inclusion of Other in the Self Scale (Aron, Aron, \& Smollan, 1992). Furthermore, in order to prevent "satisficing" (survey answering behaviors reflecting lack of attentional resources; see Miura \& Kobayashi, 2016), two items screening participants for inattention were also included (e.g., For this item, please choose No agreement), and the responses of participants who failed either item were eliminated from the analyses.

\section{Results}

Descriptive statistics, reliability of scales, cross-cultural comparisons and Pearson correlations are presented in supplementary Tables S3 and S4. As there were no crosscultural differences in inclusion of other in self, we concluded that both samples had referred to similar targets in terms of closeness. Furthermore, because positive affect and happiness were strongly correlated in both cultures, we used an aggregate mean score for subsequent analyses, and labeled it aggregate positive affect.

To test our predictions, we conducted multiple regression analyses. Culture (dummy-coded as Japan=0 and U.S.=1), perceived social expectation (mean-centered), and their interaction were included in the regression model to predict agency (desire to help) and affect. The interactions between culture and perceived social expectation on desire to help ( $\beta=-.30, p<.001)$, aggregate positive affect $(\beta=-.18, p=.02)$, and negative affect $(\beta=.16, p=.01)$ were significant. Therefore, the association between perceived social expectation and agency (simple slope Japan $b=0.09, p=.12$; simple slope U.S. $b=-0.22, p<.001$ ), as well as that between perceived expectation and aggregate positive affect (simple slope Japan $b=0.02, p=.42$; simple slope U.S. $b=-0.06, p=.09$ ), was negative in the U.S., but not in Japan. In contrast, the positive relationship between expectation and negative affect (simple slope Japan $b=-0.04, p=.17$; simple slope U.S. $b=0.07, p=.03$ ) was stronger in the U.S. Therefore, Hypotheses 1 and 2 were supported.

Next, to investigate the role of endorsement of community ethic, culture, and the interaction between community ethic (centered) and perceived social expectation (centered) were introduced in the regression model to predict agency and affect. However, none of the interactions were significant (agency $\beta=-.08, p=.14$, aggregate positive affect $\beta=.03$, $p=.51$, negative affect $\beta=-.01, p=.72$ ), so Hypothesis 3 was not supported.
Finally, to explore whether perceived social expectation hinders satisfaction of the needs for autonomy, relatedness, and competence in the U.S, but not in Japan, we tested an unconstrained model, which allowed coefficients to vary between cultures (see Figure 1; for information on the constrained model, see supplementary Tables S5 and S6).

We investigated the indirect effects of perceived social expectation on positive and negative affect (separately), through satisfaction of basic psychological needs, using bootstrapping with 1,000 samples. The indirect effect on aggregate positive affect through satisfaction of the need for autonomy was negative for Americans (estimate $=-.04$, $95 \%$ CI $[-.08,-.01]$ ), suggesting that perceived social expectation hinders satisfaction of the need for autonomy, which leads to lower positive affect. In contrast, in Japan, the indirect effect through satisfaction of the need for competence was positive (estimate $=.03,95 \%$ CI [.01, .06]). Therefore, for Japanese, perceiving social expectations to help leads to a sense of competence, which increases positive affect. Furthermore, when estimating the effects on negative affect, for Americans, the indirect effect through satisfaction of the need for autonomy was positive (estimate $=.02,95 \%$ CI $[.01, .05])$, suggesting that perceiving social expectations to help leads to lower sense of autonomy, which increases negative affect. The 95\% CI of all other indirect effects included zero (see supplementary Table S7).

\section{Discussion}

This study probed for the moderating effect of culture on the association between agentic and obligatory motivations to help (Buchtel et al., 2018; Janoff-Bulman \& Leggatt, 2002). The results indicated that Japanese internalize social expectations to help more than Americans. Our study affords further evidence for the incongruence between responding to perceived social expectations and sense of agency in Western cultures (Weinstein \& Ryan, 2010). In addition, by investigating the role of satisfaction of the needs for autonomy, competence, and relatedness, our study offers an explanation for why perceived social expectation has contrasting effects on affect in the two cultures. In line with previous research suggesting that well-being is achieved through different pathways in independent versus interdependent cultures (Kitayama, Karasawa, Curhan, Ryff, \& Markus, 2010), perceiving social expectation to help 
Gherghel, Hashimoto \& Takai: Culture moderates the association between social expectations regarding helping and positive affect
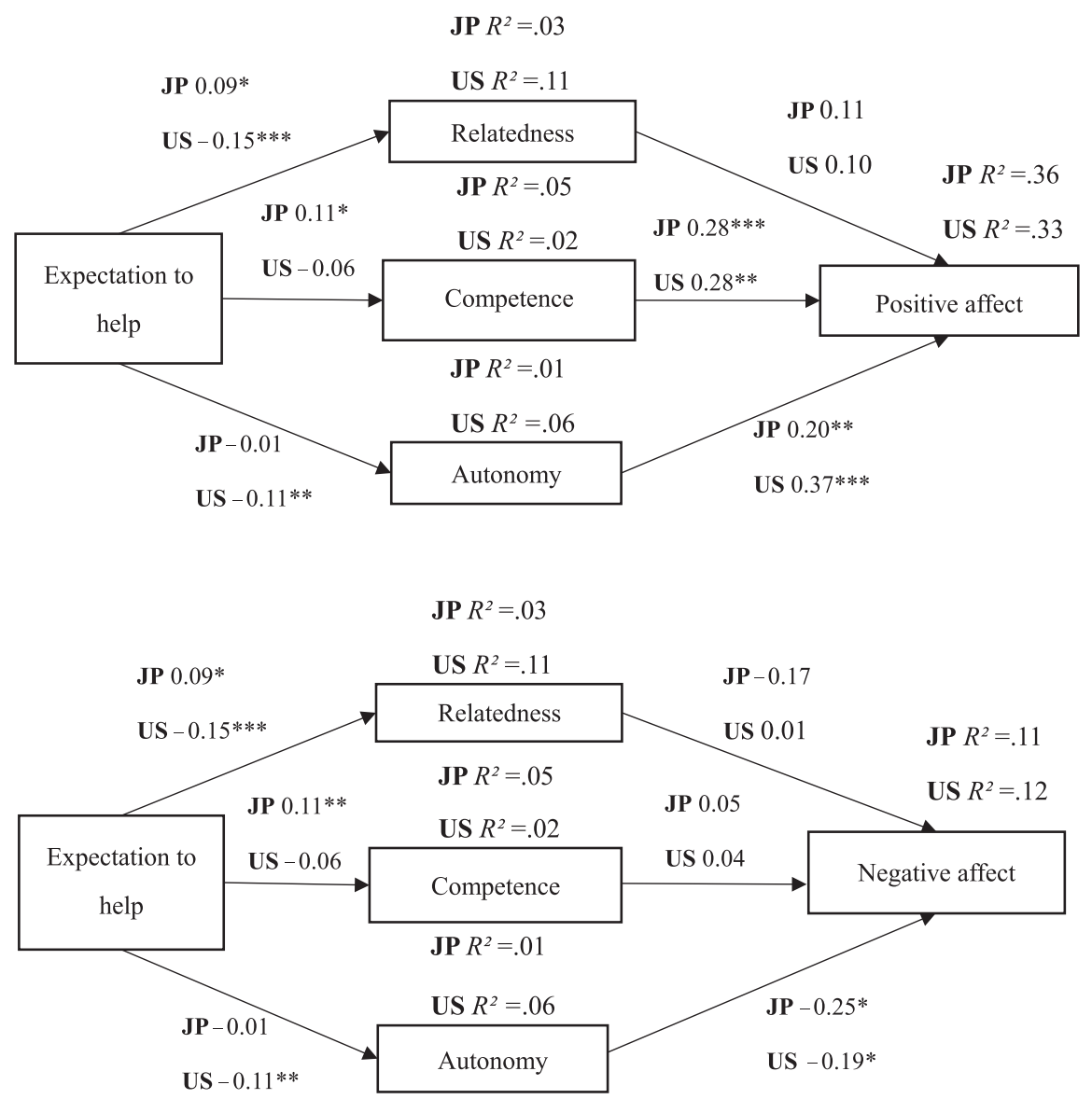

Figure 1 Unconstrained model representing the mediating effect of basic psychological need satisfaction on the relationship between perceived social expectation to help and affect. The model assumes residual covariances between mediators. Unstandardized regression coefficients are reported. JP=Japan, US=United States.

$* p<.05, * * p<.01, * * * p<.001$.

had stronger positive effects on affect for interdependent Japanese, relative to the more independent Americans, fostering a sense of being socially competent (more satisfaction of the need for competence). Given these results, Japanese derive more positive affect from expected helping, probably because being responsive to other people's needs is an important cultural task for interdependent individuals (Markus, 2016). In contrast, perceived social expectation lowered satisfaction of the need for autonomy and decreased positive affect for Americans, suggesting that social expectations are thought of as being imposing by independent individuals. Consequently, Japanese may experience more satisfaction from helping others when it is strongly expected, while the opposite would be true for Americans.
This study has some limitations. Although we asked participants to recall helping someone, to report on their past motivations, and to state their current affect, because of the correlational nature of the study, the direction of causality is unclear. Therefore, experimentally manipulating motivation is necessary in order to draw conclusions regarding causation. Another issue is that agentic and obligatory motivation were measured by only one item each, so more reliable measures of motivation need to be used in future studies. Finally, as we could not replicate the moderating effect of endorsement of community ethic on the association between obligation, agency, and affect (Gherghel et al., 2019), more research is needed in order to establish whether differences in moral discourse play a role in the 
cultural moderation effects observed. Overall, the results of this study suggest that, in opposition to the tension prevalent in Western thought between individual sense of agency and social role fulfillment, meeting social obligations might not reduce agency and satisfaction for individuals from interdependent cultures.

\section{Acknowledgment}

This research was supported by Grant-in-aid for Japan Society for the Promotion of Science Fellow number JP18J13021 to Claudia Gherghel.

\section{References}

Aron, A., Aron, E. N., \& Smollan, D. (1992). Inclusion of Other in the Self Scale and the structure of interpersonal closeness. Journal of Personality and Social Psychology, 63, 596-612.

Buchtel, E. E., Ng, L. C. Y., Norenzayan, A., Heine, S. J., Biesanz, J. C., Chen, S. X., ... \& Su, Y. (2018). A sense of obligation: Cultural differences in the experience of obligation. Personality and Social Psychology Bulletin, 44, 1545-1566.

Gherghel, C., Nastas, D., Hashimoto, T., Takai, J., \& Cargile, A. C. (2019). Culture, morality, and the effect of prosocial behavior motivation on positive affect. Ethics \& Behavior, 30, 126-149.

Guerra, V. M., Giner-Sorolla, R., \& Vasiljevic, M. (2013). The importance of honor concerns across eight countries. Group Processes and Intergroup Relations, 16, 298-318.

Janoff-Bulman, R., \& Leggatt, H. K. (2002). Culture and social obligation: When "Shoulds" are perceived as "Wants." Journal of Research in Personality, 36, 260270 .

Jiang, T., \& Gore, J. S. (2016). The relationship between autonomous motivation and goal pursuit: A crosscultural perspective. Asian Journal of Social Psychology, 19, 101-111.

Kawahito, J., Otsuka, Y., Kaida, K., \& Nakata, A. (2011).
Reliability and validity of the Japanese version of 20item Positive and Negative Affect Schedule. Hiroshima Psychological Research, 11, 225-250.

Kitayama, S., Karasawa, M., Curhan, K. B., Ryff, C. D., \& Markus, H. R. (2010). Independence and interdependence predict health and wellbeing: Divergent patterns in the United States and Japan. Frontiers in Psychology, 1,163 .

Kitayama, S., Markus, H. R., \& Kurokawa, M. (2000). Culture, emotion, and well-being: Good feelings in Japan and the United States. Cognition \& Emotion, 14, 93-124.

Markus, H. R. (2016). What moves people to action? Culture and motivation. Current Opinion in Psychology, 8, 161166.

Miller, J. G., Das, R., \& Chakravarthy, S. (2011). Culture and the role of choice in agency. Journal of Personality and Social Psychology, 101, 46-61.

Miura, A., \& Kobayashi, T. (2016). Exploring tips to detect "satisficing" in an online survey: A study using university student samples. Japanese Journal of Social Psychology, 32, 123-132.

Sheldon, K. M., \& Hilpert, J. C. (2012). The balanced measure of psychological needs (BMPN) scale: An alternative domain general measure of need satisfaction. Motivation and Emotion, 36, 439-451.

Watson, D., Clark, L. A., \& Tellegen, A. (1988). Development and validation of brief measures of positive and negative affect: the PANAS scales. Journal of Personality and Social Psychology, 54, 1063-1070.

Weinstein, N., \& Ryan, R. M. (2010). When helping helps: Autonomous motivation for prosocial behavior and its influence on well-being for the helper and recipient. Journal of Personality and Social Psychology, 98, 222244.

Wiwad, D., \& Aknin, L. B. (2017). Motives matter: The emotional consequences of recalled self- and otherfocused prosocial acts. Motivation and Emotion, 41, $730-740$. 